\title{
A new indication for elective induction of labor COVID-19 pandemic effect
}

\author{
Isha Nandal*, Surinder Pal Singh Kochar, Rajvir Kaur
}

Department of Obstetrics and Gynaecology, S. G. T Medical College, Gurugram, Haryana, India

Received: 09 September 2021

Revised: 27 November 2021

Accepted: 30 November 2021

\section{*Correspondence:}

Dr. Isha Nandal,

E-mail: ishadahiya2018@gmail.com

Copyright: () the author(s), publisher and licensee Medip Academy. This is an open-access article distributed under the terms of the Creative Commons Attribution Non-Commercial License, which permits unrestricted non-commercial use, distribution, and reproduction in any medium, provided the original work is properly cited.

\begin{abstract}
Background: Induction of labour is performed in certain circumstances which involve greater risks of waiting for the onset of spontaneous labour than the risks due to shortening the duration of pregnancy by induction. The objective of this study was to evaluate the maternal and fetal outcome in patients undergoing elective induction during COVID-19 pandemic.

Methods: This prospective observational study was conducted on 60 ANC patients with singleton pregnancy and POG >39 weeks coming to OPD with negative COVID-19 RT-PCR report. To avoid the burden of repeat testing after one week and risk of exposure to COVID-19 virus from community, patients were induced. All the data was recorded and analyzed.

Results: Most of the patients were in age group of $20-25$ years $(50 \%)$ and only $6.7 \%$ of the patients were older than 30 years. $32(53.3 \%)$ patients were multiparous and $50 \%$ of the patients were having Bishop score between 2-5 and only $8.3 \%$ had bishop score of more than 5.47 patients $(78.3 \%)$ underwent normal vagina delivery whereas 12 patients (20\%) underwent LSCS. Failure of Induction was the indication for LSCS in 5 patients $(41.7 \%)$.

Conclusions: Elective induction was found to be better option in COVID-19 negative patients. All pregnant women should be monitored for development of symptoms and signs of COVID-19 particularly if they have had close contact with a confirmed case. Pregnancy and childbirth generally do not increase the risk for acquiring SARS-CoV-2 infection but may worsen the clinical course of COVID-19 compared with nonpregnant individuals of the same age.
\end{abstract}

Keywords: Induction of labor, COVID-19, LSCS

\section{INTRODUCTION}

Induction is defined as an intervention intended to artificially initiate uterine contractions resulting in the progressive effacement and dilatation of the cervix resulting in the vaginal delivery of the baby. Pandemic caused by COVID-19 has led to a state of global health crisis. Healthcare services disruption and lock downs may also affect the management of pregnant female and their infant. ${ }^{1,2}$ Pregnant women with COVID-19 may be at increased risk for more severe illness compared with nonpregnant peers. The incubation period of COVID-19 infection can vary between 2 and 14 days. Induction of labour is performed in certain circumstances which involve greater risks of waiting for the onset of spontaneous labour than the risks due to shortening the duration of pregnancy by induction. Decisions about mode of delivery and outcomes in patients should be taken after carefully weighing of the benefits of interventions for the mother and fetus with potential risks. 


\section{Objectives}

Objectives of current study were to evaluate the maternal and fetal outcome in patients undergoing elective induction during COVID-19 pandemic.

\section{METHODS}

This prospective observational study was conducted on 60 patients at OBGYN department of SGT medical college for a period of 6 months from April to September 2020. ANC patients with singleton pregnancy with POG $>39$ weeks coming to OPD with negative COVID-19 RTPCR report were included in this study and induced. The passage and passenger were assessed and modified BISHOP calculated. Patients were induced with dinoprostone gel 3 doses at 6 hours apart. The induced patients were monitored in labor room where maternal and fetal monitoring was done with non stress test (NST) and intermittent auscultation was provided. Maternal and fetal outcomes were observed. Patients presenting with post dated pregnancy POG >41 weeks, PROM, IUGR, RH negative pregnancy, intrahepatic cholestasis of pregnancy, hypertensive disorders of pregnancy and gestational diabetes mellitus were excluded. To avoid the burden of repeat testing after one week and risk of exposure to COVID-19 virus from community, patients were induced. Prior to induction written consent was taken. All the data was recorded in Microsoft Excel sheet and analysed using SPSS 22 software.

\section{RESULTS}

Most of the patients were in age group of 20-25 years (50\%) and only $6.7 \%$ of the patients were older than 30 years (Table 1). $32(53.3 \%)$ patients were multiparous and $50 \%$ of the patients were having Bishop score between $2-5$ and only $8.3 \%$ had bishop score of more than 5. In our study, 47 patients $(78.3 \%)$ underwent normal vagina delivery whereas 12 patients $(20 \%)$ underwent LSCS (Table 2).

Table 1: Demographic profile of patients $(n=70)$.

\begin{tabular}{|lll|}
\hline Age (years) & $\mathbf{N}$ & $(\%)$ \\
\hline $\mathbf{2 0 - 2 5}$ & 30 & 50 \\
\hline $\mathbf{2 5 - 3 0}$ & 26 & 43.3 \\
\hline $\mathbf{3 0}$ & 4 & 6.7 \\
\hline Gravida & & \\
\hline Primi & 28 & 46.7 \\
\hline Multiparous & 32 & 53.3 \\
\hline
\end{tabular}

Failure of Induction was the indication for LSCS in 5 patients $(41.7 \%)$. Fetal distress was the indication in 4 patients (Table 3). Regarding neonatal outcomes, 26 $(43.3 \%)$ were male and $34(56.7 \%)$ were females. $75 \%$ of the neonates were having birth weight between $2.5-3.5$ kgs. $86.7 \%$ of neonates had APGAE score between 7-10 whereas $3.3 \%$ had APGAR score below 3 .
Table 2: Mode of delivery of patients in this study.

\begin{tabular}{|lll|}
\hline Mode of delivery & $\mathbf{N}$ & $\%$ \\
\hline Normal vaginal delivery & 47 & 78.3 \\
\hline Emergency LSCS & 12 & 20 \\
\hline Instrumentation & 1 & 1.7 \\
\hline
\end{tabular}

Table 3: Indication for LSCS $(n=12)$.

\begin{tabular}{|lll|}
\hline Indication & N & $\%$ \\
\hline Failure of induction & 5 & 41.7 \\
\hline Fetal distress & 4 & 33.3 \\
\hline Meconium stained liquor & 2 & 16.7 \\
\hline Arrest of descent & 1 & 8.3 \\
\hline
\end{tabular}

\section{DISCUSSION}

The incidence of induction of labor (IOL) is the artificial initiation of labour before its spontaneous onset to deliver the fetus and it is increasingly performed nowadays. Incidence of IOL is about $20 \%$. $^{3}$ Pregnancy doesn't make it more likely to contract COVID-19 infection than the general population but pregnancy affects the immunity, reduces functional residual volumes, elevates diaphragm and alters response to viral infections which can occasionally result in more severe symptoms. In case ofthe fetus and the neonates, the immature innate and adaptive immune systems make them highly susceptible to infections. ${ }^{4}$

The main sources of infection are the patients infected by the novel coronavirus. Asymptomatic patients infected with COVID-19 may also be a source. Transmission occurs mostly via respiratory droplets and close contact. Aerosol transmission in a relatively closed environment can also lead to infection. The induction of labor is intended for achieving a successful vaginal delivery that is as natural as possible. Depending on a patient's obstetrical and medical history, the main indications for IOL includes post-term gestation, preterm rupture of membranes (PROM) at term, PROM at near term with pulmonary maturity, intrauterine growth restriction, preeclampsia $\geq 37$ week and significant maternal disease not responding to treatment. The likelihood of success and appropriate method of induction is based on assessment of bishop score. Elective induction of labor is fast becoming a frequent indication criterion especially based on the latest scientific data. ${ }^{5}$

As per the survey published in 2021, 23\% sites reported change in cervical ripening methods and $24 \%$ noted changes to women's response to recommendations for IOL. These changes were mainly due to efforts to minimise hospital attendance. ${ }^{6}$ COVID-19 in pregnant females has shown no significant association between infection and an increased risk of miscarriage. ${ }^{7}$ Some of the contraindications for induction of labor include placenta previa, umblical cord prolapse, prior classical or inverted $\mathrm{T}$ uterine incision, significant prior uterine 
surgery, pelvic structural deformities and transverse fetal presentation. Complications that can occur during the induction of labor. Uterine tachysystole (>5 contractions $/ 10$ mins) may lead to fetal bradycardia. ${ }^{8}$ Cesarean section can be performed in cases of failed induction of labor or a non-reassuring fetal heart rate tracing.

In pregnant patients with severe COVID-19 infection, the mode of delivery is mostly caesarean section. ${ }^{9-11}$ Transferring patients from one place to another within or from hospital carries risk of exposure to both patients and health care workers. Vaginal delivery via induction of labour should be favoured to avoid unnecessary surgical complications. $^{12}$ Also there is no viral transmission reported from mother to fetus in neonates delivered vaginally in COVID-19 patients. ${ }^{13,14}$ There are some limitations to our study. The number of patients is less and therefore the result cannot be extrapolated to the whole target population.

\section{CONCLUSION}

Elective induction was found to be better option in COVID-19 negative patients. All pregnant women should be monitored for development of symptoms and signs of COVID-19 particularly if they have had close contact with a confirmed case. Pregnancy and childbirth generally do not increase the risk for acquiring SARSCoV-2 infection but may worsen the clinical course of COVID-19 compared with nonpregnant individuals of the same age.

Funding: No funding sources

Conflict of interest: None declared

Ethical approval: The study was approved by the Institutional Ethics Committee

\section{REFERENCES}

1. Burki T. The indirect impact of COVID-19 on women. Lancet Infect Dis. 2020;20:904-5.

2. Roberton T, Carter ED, Chou VB. Early estimates of the indirect effects of the COVID-19 pandemic on maternal and child mortality in low-income and middle-income countries: a modelling study. Lancet Glob Health. 2020;8:e901-8.

3. Talaulikar VS, Arulkumaran S. Failed induction of labor: Strategies to improve the success rates. Obstet Gynecol Surv. 2011;66:717-28.

4. Van Well GTJ, Daalderop LA, Wolfs T, Kramer BW. Human perinatal immunity in physiological conditions and during infection. Mol Cell Pediatr. 2017;4:4

5. Darney BG, Snowden JM, Cheng YW, Jacob L, Nicholson JM, Kaimal A, et al. Elective induction of labor at term compared with expectant management: maternal and neonatal outcomes. Obstet Gynecol. 2013;122:761-9.

6. Harkness M, Yuill C, Cheyne H. Induction of labour during the COVID-19 pandemic: a national survey of impact on practice in the UK. BMC Pregn Childbirth. 2021;21:310.

7. Yan J, Guo J, Fan C, Juan J, Yu X, Li J, et al. Coronavirus disease 2019 (COVID-19) in pregnant women: a report based on 116 cases. Am J Obstet Gynecol. 2020;45:53-9.

8. Cheng YW, Jacob L. Induction of labor. Obstet Gynecol. 2009;114(2):386-97.

9. Boelig RC, Manuck T, Oliver EA, Di Mascio D, Saccone G, Bellussi F, et al. Labor and delivery guidance for COVID-19. Am J Obstet Gynecol. 2020; 2:100110.

10. Chen H, Guo J, Wang C, Luo F, Yu X, Zhang W, et al. Clinical characteristics and intrauterine vertical transmission potential of COVID-19 infection in nine pregnant women: a retrospective review of medical records. Lancet. 2020;395:809-15.

11. Rasmussen SA, Smulian JC, Lednicky JA, Wen TS, Jamieson DJ. Coronavirus disease 2019 (COVID-19) and pregnancy: what obstetricians need to know. Am J Obstet Gynecol. 2020;222:415-26.

12. Favre G, Pomar L, Musso D, Baud D. 2019-NCoV epidemic: what about pregnancies?. Lancet Lond. 2020;395(10224):e40.

13. Breslin N, Baptiste C, Gyamfi-Bannerman C, Miller R, Martinez R, Bernstein K. COVID-19 infection among asymptomatic and symptomatic pregnant women: two weeks of confirmed presentations to an affiliated pair of New York City hospitals. Am J Obstet Gynecol. 2020:100118.

14. Zhu H, Wang L, Fang C, Peng S, Zhang L, Chang G. Clinical analysis of 10 neonates born to mothers with 2019-NCoV pneumonia. Transl Pediatr. 2020;9(1): 51-60.

Cite this article as: Nandal I, Kochar SPS, Kaur R. A new indication for elective induction of labor COVID-19 pandemic effect. Int J Reprod Contracept Obstet Gynecol 2022;11:141-3. 